\title{
Oportunidades e desafios para o desenvolvimento de sensores ambientais de baixo custo
}

\author{
Bruno Henrique Pimentel Rosado \\ Graduado em Ciências Biológicas (UFRJ), Mestre em Ecologia (UFRJ) e Doutor em \\ Biologia Vegetal (UNICAMP). Atualmente é Professor Adjunto do Departamento de \\ Ecologia da UERJ. Realiza pesquisas nos temas: Ecofisiologia Vegetal, Ecologia Funcional \\ de Plantas, Ecologia de Comunidades, Ecohidrologia e Interações Biosfera-atmosfera. É \\ professor permanente do Programa de Pós-graduação em Ecologia e Evolução da UERJ, \\ ministrando as disciplinas "Estruturas de Teorias Ecológicas" e "Diversidade funcional e \\ filogenética no estudo de estrutura de comunidades e funcionamento de ecossistemas" \\ $\bowtie$ brunorosado@gmail.com
}

Para que seja possível compreender as oportunidades e desafios do desenvolvimento de sensores ambientais de baixo custo, primeiro preciso dar uma breve panorâmica da minha própria formação e sobre como é importante para qualquer profissional ter entendimento sobre diversos campos do conhecimento. Desde o início da graduação a minha linha de pesquisa não mudou. Meu principal interesse foi e continua sendo a avaliação dos mecanismos de respostas das plantas, em diferentes níveis hierárquicos, às mudanças ambientais. Os mecanismos de resposta consistem em avaliar características morfológicas e fisiológicas capazes de descrever o grau de vulnerabilidade das espécies a fatores como seca e maior radiação solar. Tal avaliação não se faz sem o uso de diversos sensores, de termômetros a estações meteorológicas, capazes de permitir a aquisição de dados descrevendo a natureza.

O interesse pela Ecofisiologia Vegetal e a forma como plantas poderiam afetar processos ecohidrológicos esteve sempre atrelado a uma necessária compreensão de outras ciências tais como Engenharia, Física, Matemática, Eletrônica e Programação. Entender a biologia de cada espécie, seus níveis de tolerância, quais fatores acarretariam maior crescimento ou mortalidade de plantas depende diretamente de compreender o funcionamento de sensores, como calibrá-los, descobrir quando estavam com mal funcionamento e, eventualmente, consertá-los. Sensores, portanto, nos permitem descrever o mundo natural.

O ápice desta necessidade ocorreu durante a realização do meu doutorado quando, munido de uma caixa de ferramentas e um laptop, eu adentrava a Mata Atlântica para coletar 
os dados de sensores que mediam a cada trinta minutos, durante um ano, informações sobre fluxo de água no xilema das árvores. Não raramente, a umidade danificava as conexões dos sensores, do painel solar e da bateria que alimentavam os mesmos, os cabos eram roídos por animais e formigas construíam ninhos nos dispositivos. Era preciso consertar e soldar. Era preciso, com o laptop que eu trazia comigo, reprogramar os sensores em campo, inclusive nos dias chuvosos no meio da Mata Atlântica.

Após esse breve relato, fica claro que um dos maiores equívocos na construção do conhecimento é imaginarmos que disciplinas das diferentes áreas do conhecimento (e.g., Exatas, Biológicas e Humanas) não dialogam entre si. Ainda que separemos áreas, disciplinas e cursos, tais separações não existem na Natureza. São puramente artificiais. Um organismo, seja ele qual for, não sabe a qual Departamento ou Instituto ele pertence. Ainda que cognitivamente nosso entendimento da natureza funcione a partir da categorização dos seus elementos - até mesmo o tempo em dias da semana e meses - a atividade científica deve ultrapassar tais categorias. Em muitos casos estas categorias são completamente arbitrárias e artificiais para respondermos a uma determinada pergunta de interesse. Mais do que nos denominarmos especialistas em uma determinada área (i.e., categoria), é preciso a consciência da importância do conjunto de ferramentas, conceitos, técnicas e teorias que perpassam múltiplas disciplinas e que permitirão a resolução de um problema.

Neste sentido, o desenvolvimento de sensores ambientais ilustra como o domínio de disciplinas aparentemente distantes da biologia tem permitido o avanço em áreas diversas em função da construção de câmeras acopladas a drones para monitoramento ambiental e de sensores capazes de mensurar fluxo de água em plantas. Em um cenário de escassez de recursos para a ciência, pensar projetos apenas com base nos equipamentos que estão à venda ou naqueles que podemos comprar, é ficar à mercê de um mercado que cobra valores exagerados sobre equipamentos científicos e que sequer produz o que não gerar lucro. $\mathrm{Na}$ verdade, lucro é a construção de um conhecimento que é bom para a ciência e para a sociedade, não do que é bom para o mercado e isso pode ser alcançado a partir da elaboração de equipamentos feitos em escolas, Universidades e em casa.

Mas como desenvolver sensores, drones e robôs em casa ou na Universidade? A criação de uma plataforma eletrônica, Open Source e de baixo custo como o Arduino representou um grande avanço no aprendizado de eletrônica, física e programação e, consequentemente, na execução de projetos de baixo custo nas mais diferentes áreas. Uma 
rápida busca na internet mostrará cursos gratuitos sobre Arduino, como construir rôbos, drones, estações meteorológicas e equipamentos diversos. Com estas ferramentas disponíveis é possível construir uma estação meteorológica com sensores de luz, água no solo, umidade relativa, temperatura do ar e precipitação por cerca de cem reais, ou comprá-la por aproximadamente vinte mil reais no mercado. Revistas científicas internacionais também têm publicado artigos sobre o desenvolvimento de equipamentos usando plataformas como Arduino ou ressaltando a importância das mesmas para a pesquisa na área ambiental. Ainda, mesmo a comercialização de sensores ou qualquer outro projeto usando Arduino é possível desde que seguindo as condições da licença de uso da plataforma - o que abre várias possibilidades para estudantes de biologia e de outras áreas.

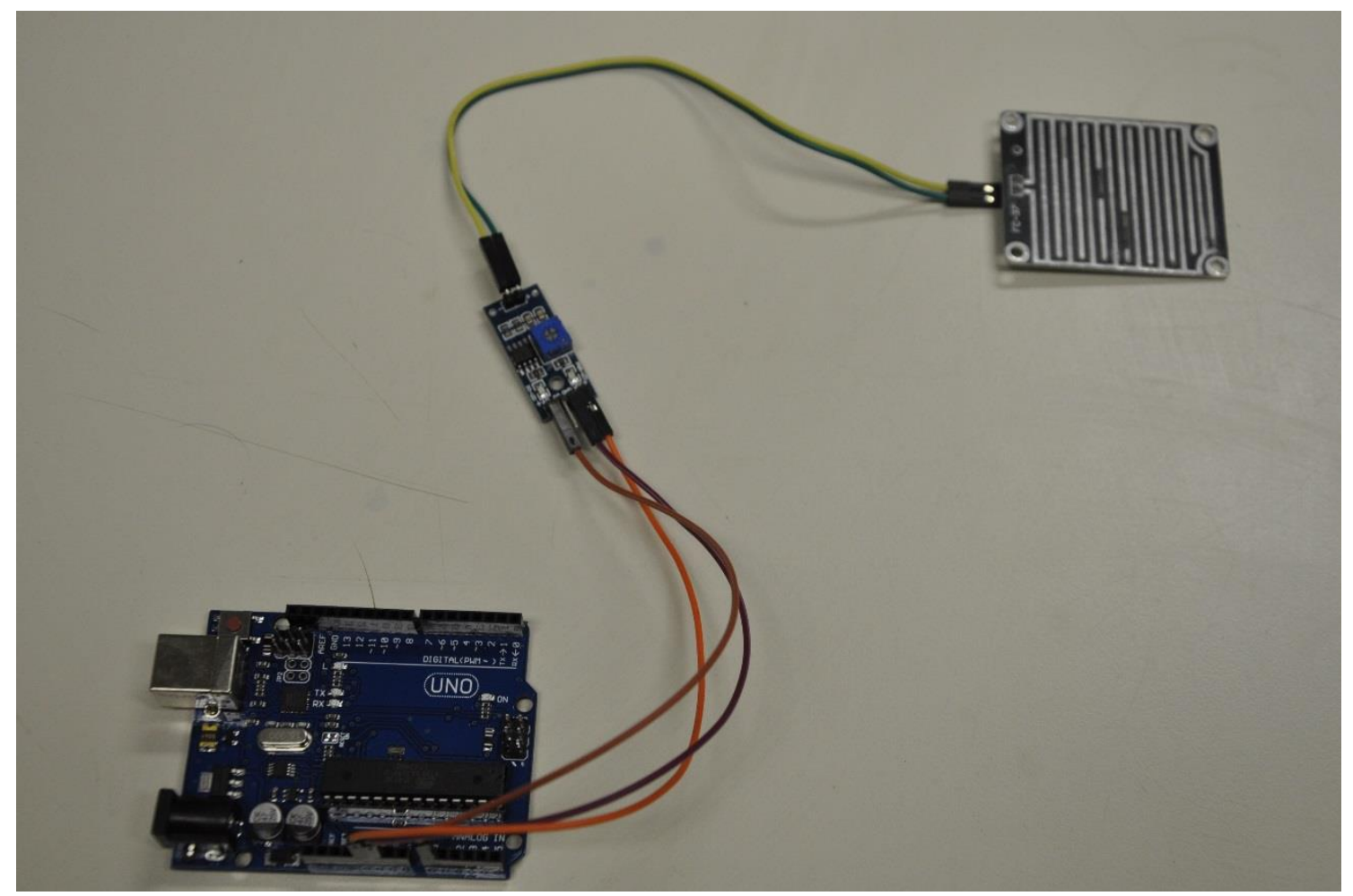

Figura 1. Exemplo de uso da plataforma Arduino (modelo Arduino Uno). Plataforma conectada a um sensor de chuva (placa à direita da foto).

Fonte: Própria.

As ferramentas existem e estão facilmente acessíveis, uma busca rápida na internet permitirá a qualquer pessoa adquirir todo o necessário para a elaboração do seu projeto. Mas para executá-lo, por mais ecológico que seja o foco do projeto, o desafio para os interessados na área ambiental é também entender o que é a Lei de Ohm, o que são capacitores, resistores, 
multímetros, microcontroladores, bytes e bits. É difícil, mas não é impossível. Além do mais, nada mais gratificante do que costurar diferentes áreas do conhecimento, mas isso não precisa ser realizado individualmente. $O$ advento desta tecnologia acessível e de baixo custo não significa que todo este aprendizado e desenvolvimento devem ser feito em isolamento. É a oportunidade para que, nas Universidades, por exemplo, sejam feitas parcerias e trocas de saberes entre profissionais de diferentes Institutos e Faculdades. E, quem sabe, a criação de disciplinas ministradas por biólogos e engenheiros.

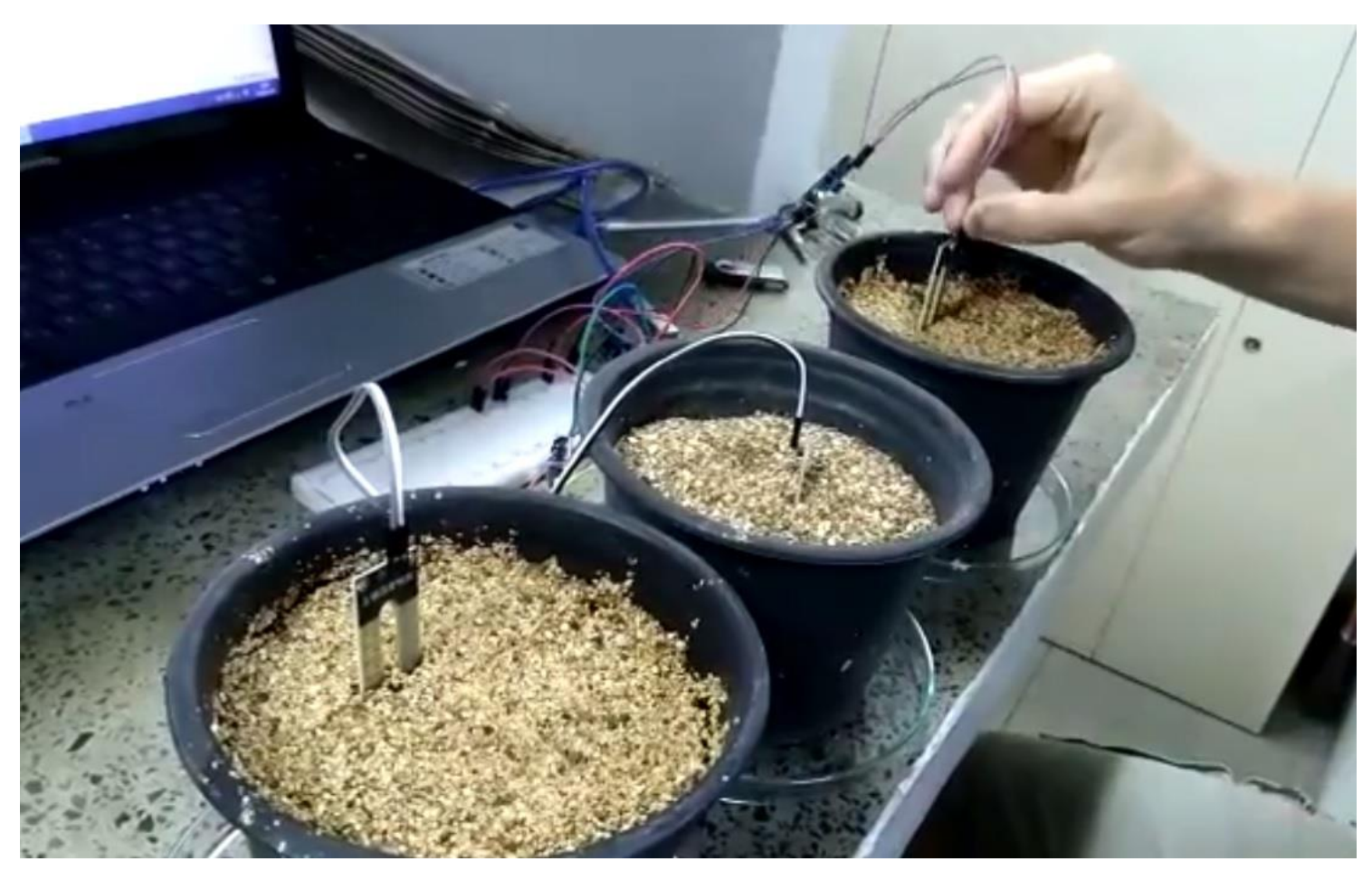

Figura 2. Exemplo de uso da plataforma Arduino (modelo Arduino Uno). Plataforma conectada a sensores de água no solo. Na foto observam-se três sensores de água solo, um sensor em cada vaso. Fonte: Própria.

Apesar de o mundo profissional levar a uma ideia da necessidade da competitividade como receita para o sucesso, o desenvolvimento de sensores de baixo custo mostra que é a cooperação, e não a competição, a força motriz na construção de um conhecimento compartilhado, de livre acesso e, portanto, mais justo para toda a sociedade. 


\section{AGRADECIMENTOS}

À Profa. Denise Espellet Klein (UNIRIO) pelas sugestões no manuscrito e aos Programas Jovem Cientista do Nosso Estado (FAPERJ № E-26/203.199/2016) e Prociencia pelo suporte.

\section{REFERÊNCIAS}

Arduino cc. .Disponível em: <https://www.arduino.cc>. Acesso em: 2/10/2018.

BAKER, E. Open source data logger for low-cost environmental monitoring. Biodiversity Data Journal, v. 2, p. e1059, 2014. Disponível em: <http://bdj.pensoft.net/articles.php?id=1059>. .

MARVIN, D. C.; KOH, L. P.; LYNAM, A. J.; et al. Integrating technologies for scalable ecology and conservation. Global Ecology and Conservation, v. 7, p. 262-275, 2016. Elsevier B.V. Disponível em: <http://dx.doi.org/10.1016/j.gecco.2016.07.002>. .

MINER, G. L.; HAM, J. M.; KLUITENBERG, G. J. A heat-pulse method for measuring sap flow in corn and sunflower using 3D-printed sensor bodies and low-cost electronics. Agricultural and Forest Meteorology, v. 246, n. May, p. 86-97, 2017. Elsevier. Disponível em: <http://dx.doi.org/10.1016/j.agrformet.2017.06.012>. .

SOKAČ, M.; DURASEK, P.; BAČIĆ, I.; PUŠKARIĆ, S. UAV application in ecology: Data collecting with quad-copter equipped with Arduino based measurement platform. Proceedings Elmar - International Symposium Electronics in Marine, v. 2016-Novem, n. September, p. 233-236, 2016. 